\title{
CONGRESOS REGIONALES REALIZADOS
}

\author{
10 Congreso Regional de Tecnología: \\ (SIN TEMA) \\ Sede: Facultad de Arquitectura y Urbanismo - Universidad Nacional de La Plata \\ (Argentina), 24 y 25 de Abril de 2008. \\ 20 Congreso Regional de Tecnología: \\ EL PENSAMIENTO TECNOLÓgICO APROPIADO PARA LA GESTIÓN SUSTENTABLE DEL \\ HÁBITAT
}

Sede: Facultad de Arquitectura y Urbanismo - Universidad Nacional de La Plata (Argentina), 24 y 25 de Abril de 2008.

\begin{tabular}{|c|}
\hline Congreso Regional de Tecnología: \\
\hline FORMACIÓN UNIVERSITARIA PARA LA CONSTRUCCIÓN DEL HÁBITAT \\
\hline
\end{tabular}

Litoral (Argentina), 1 y 2 de Julio de 2010.

Congreso Regional de Tecnología:

INNOVACIÓN TECNOLÓGICA PARA LA SUSTENTABILIDAD EN ARQUITECTURA

Sede: Facultad de Arquitectura y Urbanismo - Universidad Nacional del Nordeste (Argentina),8, 9 y 10 de Junio de 2011.

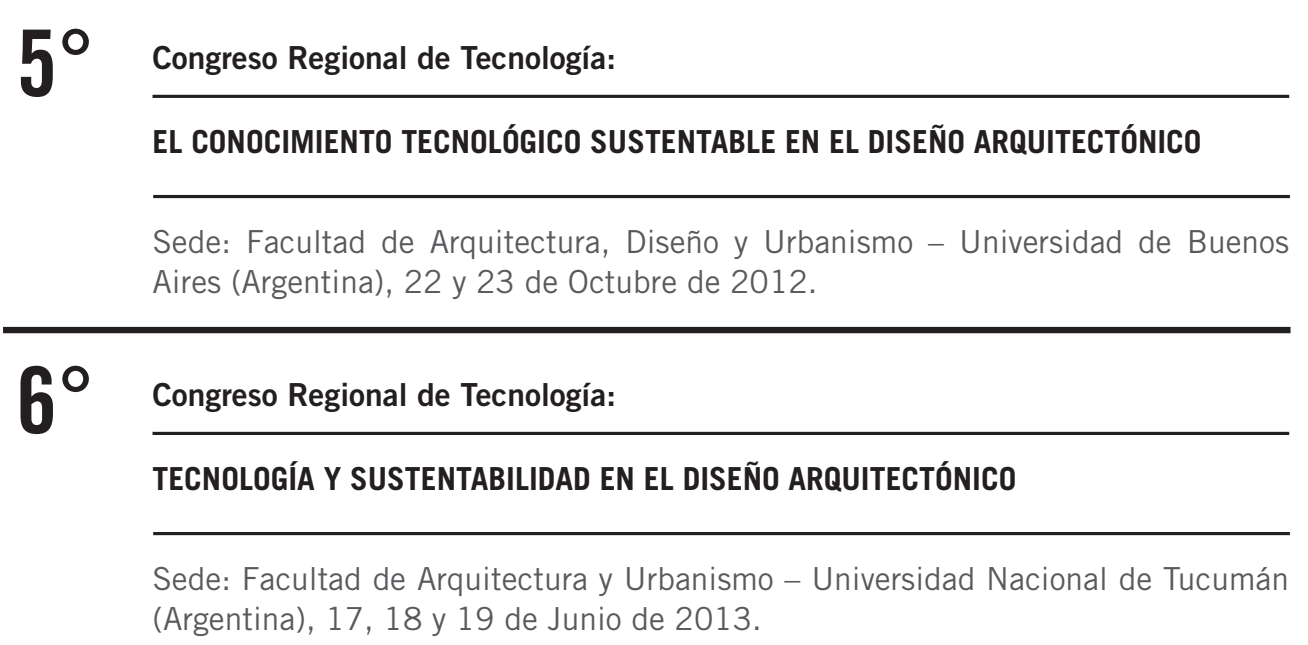

